(ISSN: 2610-9182)

\title{
Medical Students' Reactive Anxiety as a Quality Criterion for Distance Learning during the SARS-COV-2 Pandemic
}

\author{
Maria V. Sankova ${ }^{1}$, Olesya V. Kytko ${ }^{1}$, Yuriy L. Vasil'ev ${ }^{1}$, Olga Yu. Aleshkina ${ }^{2}$, \\ Ekaterina Yu. Diachkova ${ }^{1 *}$, Hadi M. Darawsheh ${ }^{3}$, Aleksandr V. Kolsanov ${ }^{4}$, \\ Sergey S. Dydykin ${ }^{1}$
}

${ }^{1}$ I.M. Sechenov First Moscow State Medical University (Sechenov University), 8-2 Trubetskaya St., 119991, Moscow, Russia

${ }^{2}$ V.I. Razumovsky Saratov State Medical University, 112-2 Bolshaya Kazachya St., 410012, Saratov, Russia

${ }^{3}$ Moscow Dental Center Vin Clinic, 15 Bolshaya Polyanka, St., 119180, Moscow, Russia

${ }^{4}$ Samara State Medical University, 89 Chapaevskaya St., 443099, Samara, Russia

\begin{abstract}
Background: Numerous studies have shown an effect of rapidly spreading SARS-COV-2 on combined anxiety-depressive disorders and maladjustment syndrome occurrences. Objective: To determine the primary medical students' reactive anxiety level and the final scores of their educational progress in distance learning during the SARS-COV-2 pandemic. Materials and Methods: The study involved 824 students at medical universities in Saratov and Moscow. The assessment of the reactive anxiety level was carried out according to the State-Trait Anxiety Inventory, STAI; the average score of students' academic performance was calculated according to the data of the technological platform "1C: Enterprise" version 8.4.1. The survey was completed during distance learning in May 2020. The quality of distance learning was compared to a similar score for 2019, when students were trained in a traditional way. Statistical analysis was conducted using Statistica 6.0. Results: It was shown the presence of moderately severe disorders among the primary medical students according to the average score of reactive anxiety $(43.28 \pm 12.85)$, that expressed more in females $\mathrm{s}(\mathrm{p}<0.05)$, After distance learning, lasting $25 \%$ of the whole course, the overall performance score in theoretical knowledge did not change significantly $(p>0.05)$ but the practical skills suffered much especially in time trend $(\mathrm{p}<0.05)$. Novelty: It was found that a high level of the reactive anxiety negatively affects the students' adaptive capabilities and the education quality. The specificity of programs at different faculties can determine the state of the students' psychological status. Findings: Timely transition to online classes during pandemics helps to preserve the students' mental well-being and the quality of the educational process. The duration of distance learning for a practical course should not exceed $25 \%$ of the whole course.
\end{abstract}

\section{Keywords:}

SARS-COV-2 Pandemic

Medical Students;

Reactive Anxiety;

Distance Learning;

Education Quality;

Theoretical Knowledge;

Practical Skills.

Article History:

Received: $\quad 08 \quad$ April 2021

Revised: $\quad 02 \quad$ July 2021

Accepted: $09 \quad$ July 2021

Published: 14 July 2021

\section{1- Introduction}

Numerous studies have shown that the rapidly SARS-COV-2 spreading was accompanied by significant changes in the lifestyle and material status of millions of people. This, combined with the increasing probability of contamination, constant worrying about the loved ones, permanent need to use personal protective equipment, the flow of negative information, can be considered as a significant risk factor for the occurrence of combined anxiety-depressive disorders

\section{* CONTACT: Secu2003@mail.ru}

DOI: http://dx.doi.org/10.28991/esj-2021-SPER-07

(C) 2021 by the authors. Licensee ESJ, Italy. This is an open access article under the terms and conditions of the Creative Commons Attribution (CC-BY) license (https://creativecommons.org/licenses/by/4.0/). 
and maladjustment syndrome in the current pandemic [1-5]. The duration of this emergency and the significance of changes in a specific area can determine the development of a cumulative stress effect [6]. Moscow is stable leading in number of SARS-COV-2 cases among other Russian regions, that may cause more expressed psycho-pathogenic reactions among mega-city residents [7].

One of the most vulnerable population groups in the current situation are primary students, especially students at medical universities, who have sanitary-epidemiological problems superimposed on the difficulties of adapting to the educational environment specifics [8]. Yesterday's schoolchildren must memorize a large amount of educational and professional information, study the layer-by-layer human body structure and the mutual organs' positions, learn to perform complex surgical actions and operations [9]. The sudden introduction of distance learning during the period of rapidly SARS-COV-2 spreading was accompanied by additional difficulties such as technical problems, lack of necessary equipment and skills for working in a distance format [10]. It was found that a high level of anxiety negatively affects the students' adaptive capabilities and the education quality [11]. In this regard, it was especially important to study the students' psychological state and indicators of their academic performance during the SARS-COV-2 pandemic in distance learning.

\section{1-1-Objective}

To determine the reactive anxiety level in primary students at the medical university and the final scores of their educational progress in distance learning during the SARS-COV-2 pandemic, to develop the opportunities that this education form opens and specific recommendations for its effective implementation.

\section{2- Materials and Methods}

The study involved 722 primary medical students of the V.I. Razumovsky Saratov State Medical University (V.I. Razumovsky SSMU), whose age on average was $18.44 \pm 1.09$ years. Thereby two age subgroups were formed to establish the age-related characteristics of the reactive anxiety's level (16, 0-18.5 years and 18.5-30, 0 years). There were 197 males $(27.29 \%)$, and 525 females $(72.71 \%)$, thus the revealed changes were analyzed depending on gender. The respondents included students of the medical $416(57.61 \%)$, pediatric $146(20.22 \%)$, medical-preventive 51 (7.08\%) and stomatological $109(15.09 \%)$ faculties, which made it possible to compare the behavioral position of students depending on the specifics of the program they studied. A group of primary students of the medical faculty of the Sechenov University in the amount of 102 people, whose average age was $19.59 \pm 1.67$ years, was additionally recruited to conduct comparative analysis of the reactive anxiety and academic performance between medical students, studying in regional city and Moscow.

The reactive anxiety was assessed according to the State-Trait Anxiety Inventory, STAI scale [12], as the state of the subject at a present moment, which is characterized by subjectively experienced emotions: tension, anxiety, concern, nervousness in each specific situation. This condition occurs as an emotional response to an extreme or stressful situation, such as a SARS-COV-2 pandemic. Interpreting the results, the following anxiety grades were used: up to 30 points low, 31 - 44 points - moderate; 45 or more - high. The average score of students' academic performance was calculated according to the data of the technological platform "1C: Enterprise" version 8.4.1 [13] as the arithmetic mean (M) with its error $(\mathrm{m})$. The survey was completed on the distance learning during the first wave of the SARS-COV-2 pandemic in May 2020. The quality of distance learning was compared to a similar academic performance score for 2019, when students were trained in a traditional way. The indicators of both the theoretical knowledge and practical skills were assessed. The percentage of the distance learning duration to the whole studying course was $27.7 \pm 3.26 \%$.

The work fully complied with the requirements of the local ethics committee of the Sechenov University (Protocol No. 04-19 dated 06.03.2019) and the norms of the Helsinki Declaration. Statistical analysis was carried out using the Statistica 6.0. The reliability of differences in quantitative indicators was checked by the Student's test (normal distributions) and Mann-Whithey test (not normal distributions), qualitative indicator was checked by Fisher's test, the level of significance was determined at $\mathrm{p}<0.05$.

\section{3- Results}

The intensity of the stress factors' influence on the primary students of V.I. Razumovsky SSMU, who were on distance learning during the first wave of SARS-COV-2 pandemic, was determined by assessing the level of reactive anxiety, which for the general group was $43.28 \pm 6.43$, indicating a moderate anxiety. This was due to the fact that overwhelming majority of respondents had a moderate $(45.3 \pm 3.63 \%)$ and high $(39.9 \pm 3.57 \%)$ levels (Figure 1) that significantly differed from the percentage of students with low anxiety $(14.8 \pm 2.59 \%)$. The most significant statements for medical students at this period were the lack of complete peace of mind, inner satisfaction, a sense of freedom and joy. More often the respondents noted that they cared about possible failures, their feelings of stiffness and tension. 


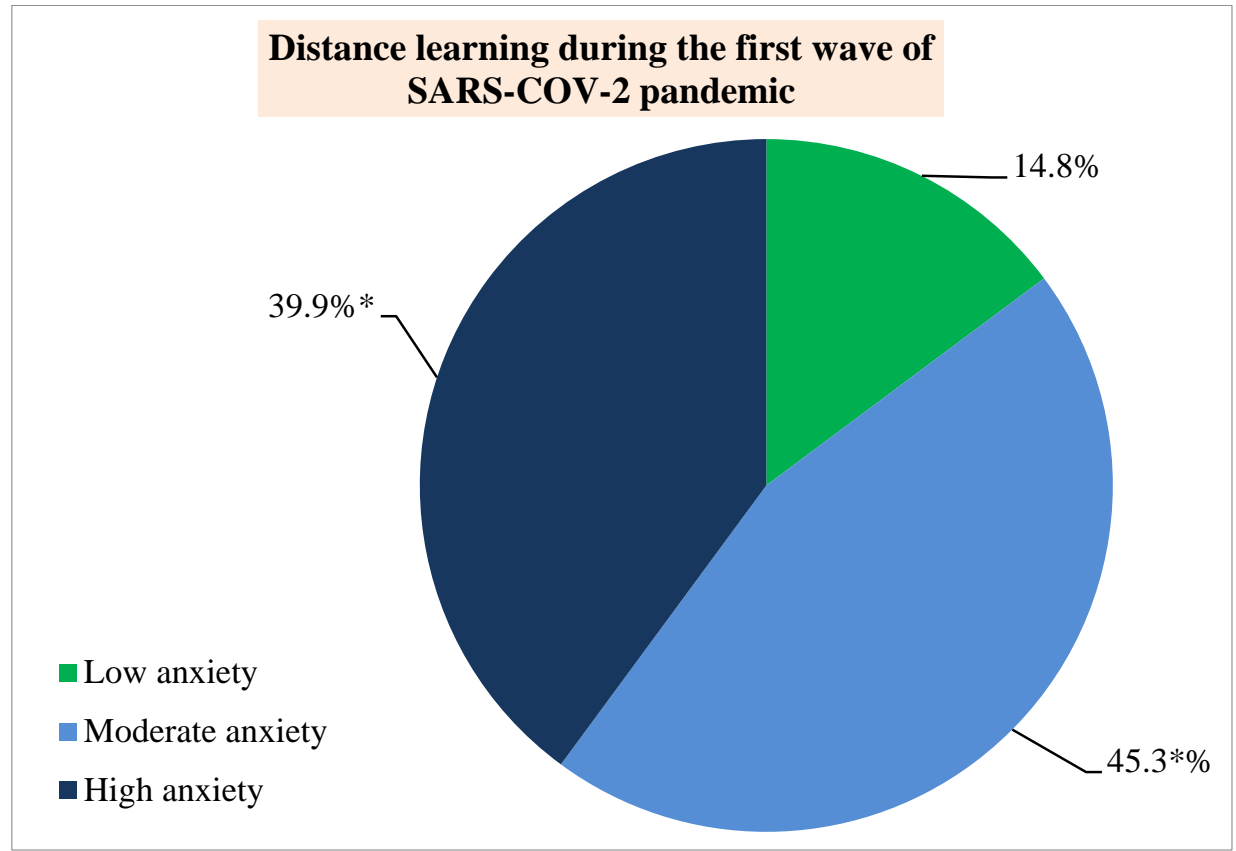

Figure 1. Distribution of V.I. Razumovsky SSMU students depending on the reactive anxiety's level. Note: * Significant differences in comparison with the percentage of students with low anxiety, $p<0.05$.

It was found that the reactive anxiety indicator depended on gender and age (Figure 2).

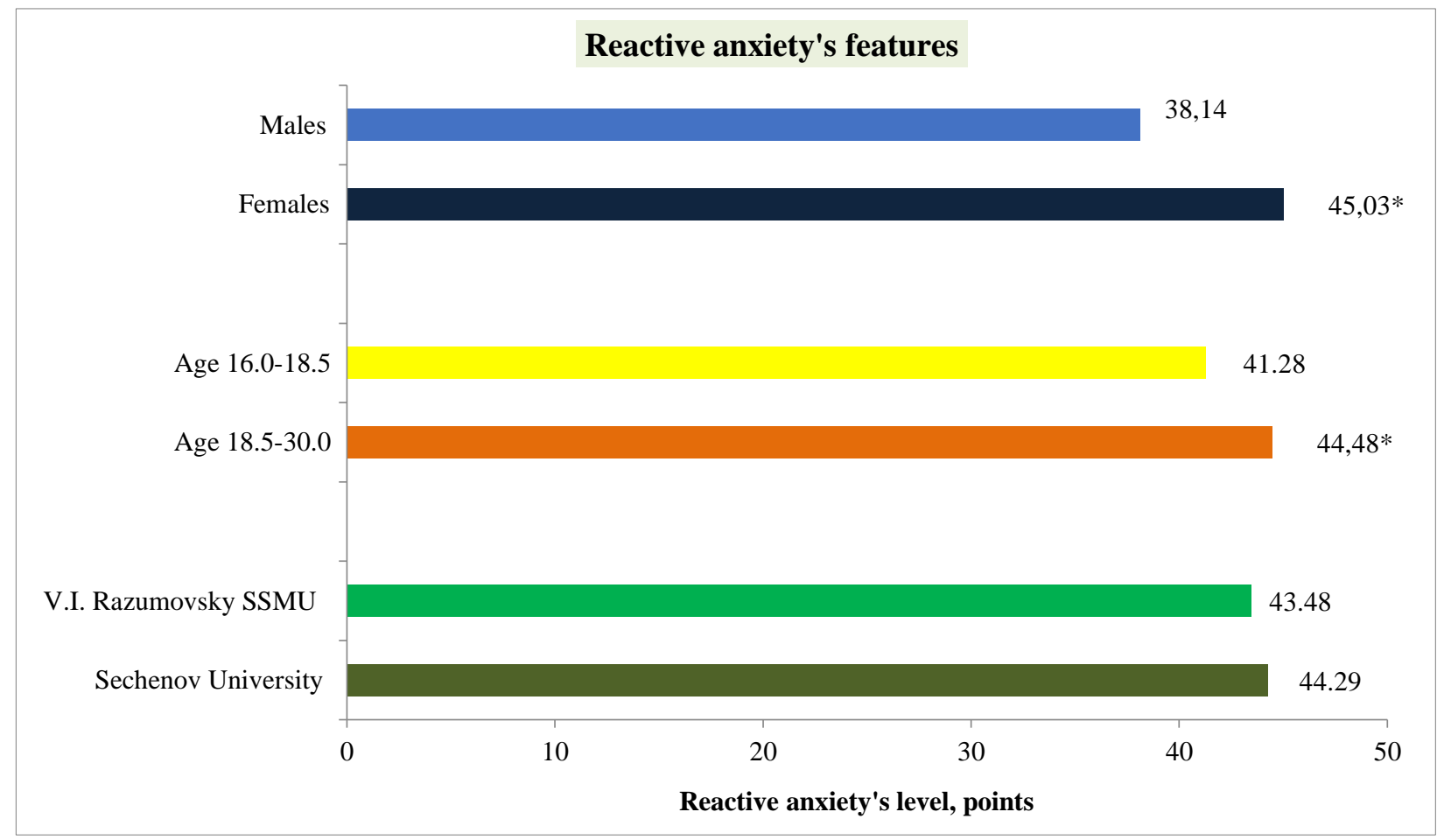

Figure 2. The reactive anxiety's level of medical students depending on gender, age and region. Note: * Significant differences in comparison with the other subgroup, $p<0.05$.

Thus, the state of females in comparison with males was characterized by more intensely felt emotions: tension, anxiety, and nervousness in these specific conditions (45.03 \pm 2.19 and $38.14 \pm 1.44$, respectively, $\mathrm{p}<0.05)$. There was a significant increase in the reactive anxiety to the current stressful situation with age $(41.28 \pm 1.41$ and $44.48 \pm 1.74$, respectively, $\mathrm{p}<0.05)$.

Interesting data were obtained comparing the behavioral position of students from different faculties (Figure 3). So, the highest score of reactive anxiety was characterized by students of the pediatric faculty $(46.98 \pm 2.01$, p <0.05), in the second place in terms of anxiety was the medical faculty $(42.99 \pm 1.97, \mathrm{p}<0.05)$, then the stomatological faculty $(39.48$ $\pm 1.45, \mathrm{p}<0.05)$. The students of the medical-preventive faculty felt the most relaxed on the distance learning $(36.37 \pm$ $1.53, \mathrm{p}<0.05)$. 


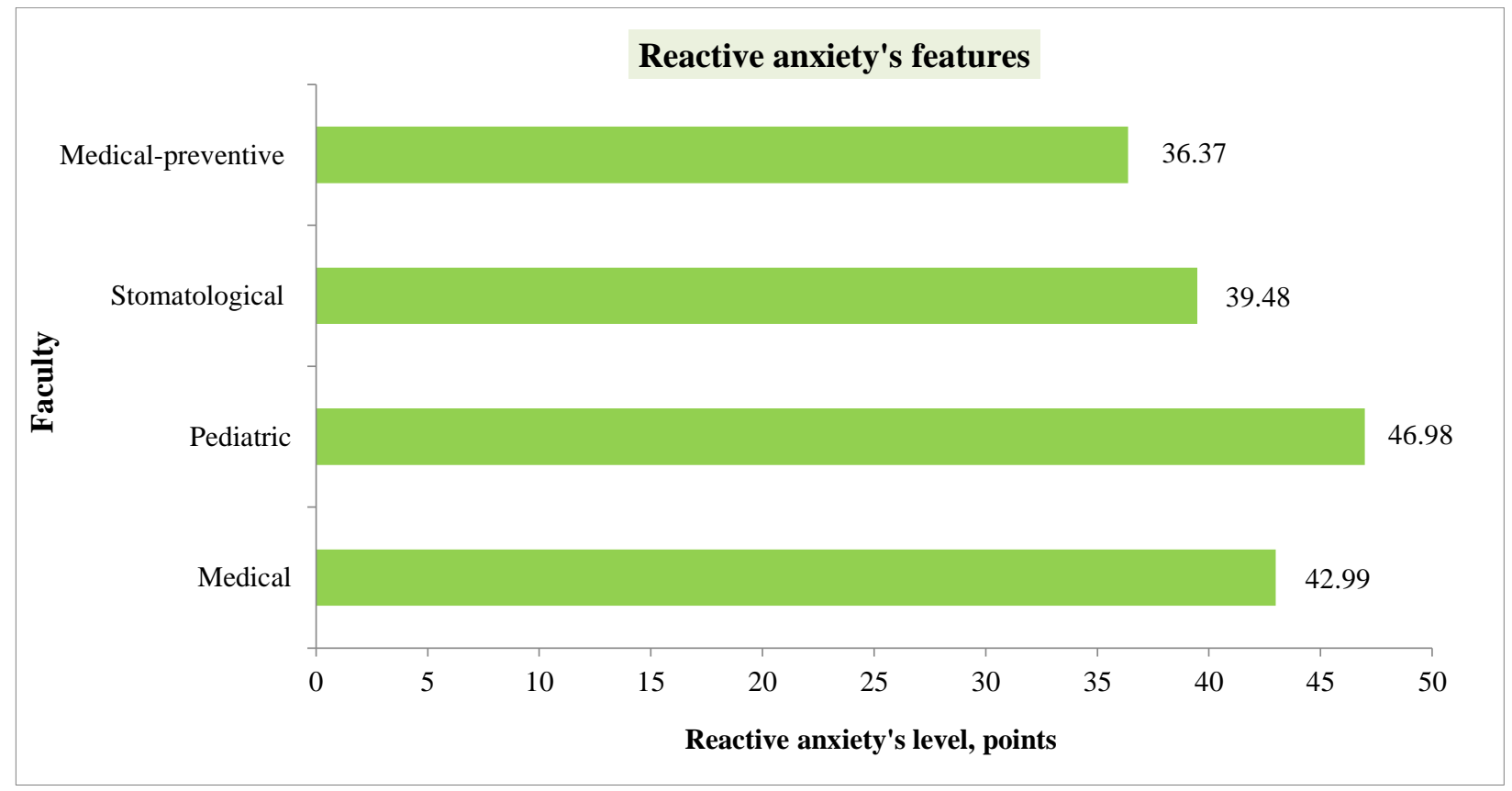

Figure 3. The reactive anxiety's level of medical students depending on the faculty program specifics.

Comparison of the students' psychological state of the medical faculty of a regional medical university (V.I. Razumovsky SSMU) and a megalopolis university (Sechenov University), studying in a distance format (Figure 2), revealed the absence of significant differences between the level of their reactive anxiety $(42.99 \pm 1.97$ and $44.29 \pm 1.81$, respectively).

Considering that the actual psychological state of students significantly affects the success of their education and their formation as future specialists, controlling of the average scores of their academic performance was carried out (Figure 4).
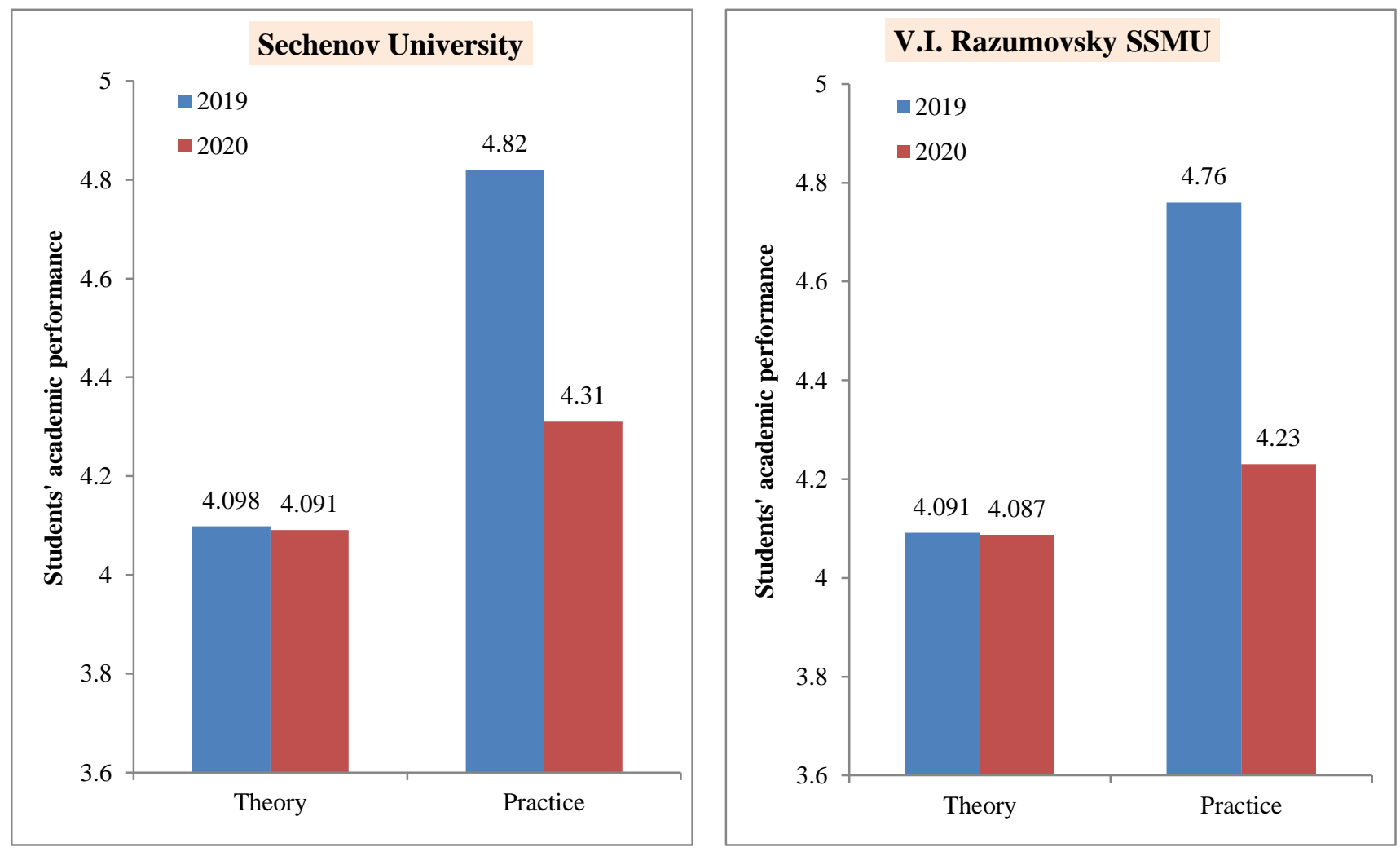

Figure 4. The average score of students' academic performance at Sechenov University and V.I. Razumovsky SSMU for 2019-2020. Note: $\downarrow$ A downward trend in academic performance indicators compared to 2019, $\mathbf{p}<0.05$. 
The introduction of distance learning, which in terms of duration was about a quarter of the whole training course, did not affect the quality of theoretical knowledge at all (Figure 4): for both universities the average score for theoretical part of education decreased less than 0,005 points $(\mathrm{p}>0.05)$; also, there was no significant difference in average score for theory between Sechenov University and V.I.Razumovsky SSMU. At the same time, the effectiveness of acquiring practical skills and abilities tended to decrease $(\mathrm{p}<0.05)$ : for Sechenov University it was significant fall of average score from 4,82 (2019 year) to 4,31 (2020 year) points ( $\mathrm{p}<0.05$ ), and for V.I.Razumovsky SSMU it was loss of 0,53 points $(\mathrm{p}<0.05)$. The significant difference in average practical skills of medical students between both Universities was not found $(\mathrm{p}>0.05)$.

\section{4- Discussion}

It was found in our study that the whole group of medical primary students on distance learning during the first wave of the SARS-COV-2 pandemic were characterized by a moderate level of reactive anxiety, which was comparable to the corresponding indicators of medical students studying in the traditional way in the absence of unfavorable sanitaryepidemiological situation, established by Racic M et al. (2017), which showed that the majority of students had moderate anxiety (70.6\%) and only $1.6 \%$ showed manifestations of a high degree of stress ( $p<0.001)$ [14]. Correction of anxiety disorders in medical students during the period of the rapidly SARS-COV-2 spreading is associated, first of all, with the timely introduction of distance education, which was accompanied by the elimination of such significant stress factors as the risk of being infected, anxiety about the danger of infecting loved ones and the constant need for use personal protective equipment, noted in a number of studies as high stress predictors during a pandemic [15-18]. Analysis of the identified psychological disorders depending on gender and age showed that they are more expressed in females and in persons of older age, which is consistent with the data of previous studies $[15,16,19,20]$. Some similar results Luibl et al. (2021) during the examination of first-course medical students' mental status with some parameters of Antonovsky model found that psychological stress and depression in students significantly affected their resilience and sense of coherence, besides resilience was significantly less in female students $(\mathrm{p}<0.01)$ [21].

According to results of our research timely transition to online classes during the period of the rapidly SARS-COV2 spreading made it possible to correct the growth of anxiety disorders in students, helped to stabilize their psychological status, which was of great importance for maintaining the effectiveness of the educational process. Thus, with distance learning, lasting $25 \%$ of the whole course, the total score of the quality of the obtained theoretical knowledge and practical skills did not change significantly and remained at the same level as it was in 2019 .

The difficulties of literature analysis depend on the lack of recent studies about medical students' anxiety on different faculties and connection with the changes of academic scores, and theoretical knowledges and practical skills especially during SARS-COV-2 pandemic. Scientists are more interested in research of the anxiety level and possible burnout in medical students depending on age, sex, country and even education semester [22-24]. Although now there is some research about anxiety in medical students in the SARS-COV-2 pandemic condition but only for vaccination question attitude solution [25].

The structure of students' reactive anxiety, depending on the specifics of the studied program, is primarily associated with the features of teaching anatomy at these faculties, with varying degrees of program complexity and, accordingly, with different requirements for knowledge control [26]. This biomedical discipline is the most significant for students of the medical and pediatric faculties, who need to master in details large amounts of information on the whole organism's structure and to gain practical skills. The lack of visual preparations and the possibility of training practical skills in the conditions of distance learning complicated the educational process and could cause higher anxiety scores among students of these faculties. The program specificity of the pediatric faculty is the additional study of the morphological and functional structural features of the child's body, depending on age, which significantly complicates the task of these students and can cause the highest score of the revealed changes. Dental students require a deep understanding of only the maxillofacial area. The profile of the medical-preventive faculty at the initial stages of training is more focused on learning theoretical disciplines, which can be well acquired in a distance format. Although, more concerns now students and staff separated in relationship to body donation for practical anatomy skills and possible disease transmission COVID-19 risk factor during learning as what discussed in article of Brassett et al. (2021) on example of Universities of Great Britain, Ireland and Germany [27].

Methods and research results can be found in following flowchart (Figure 5). 


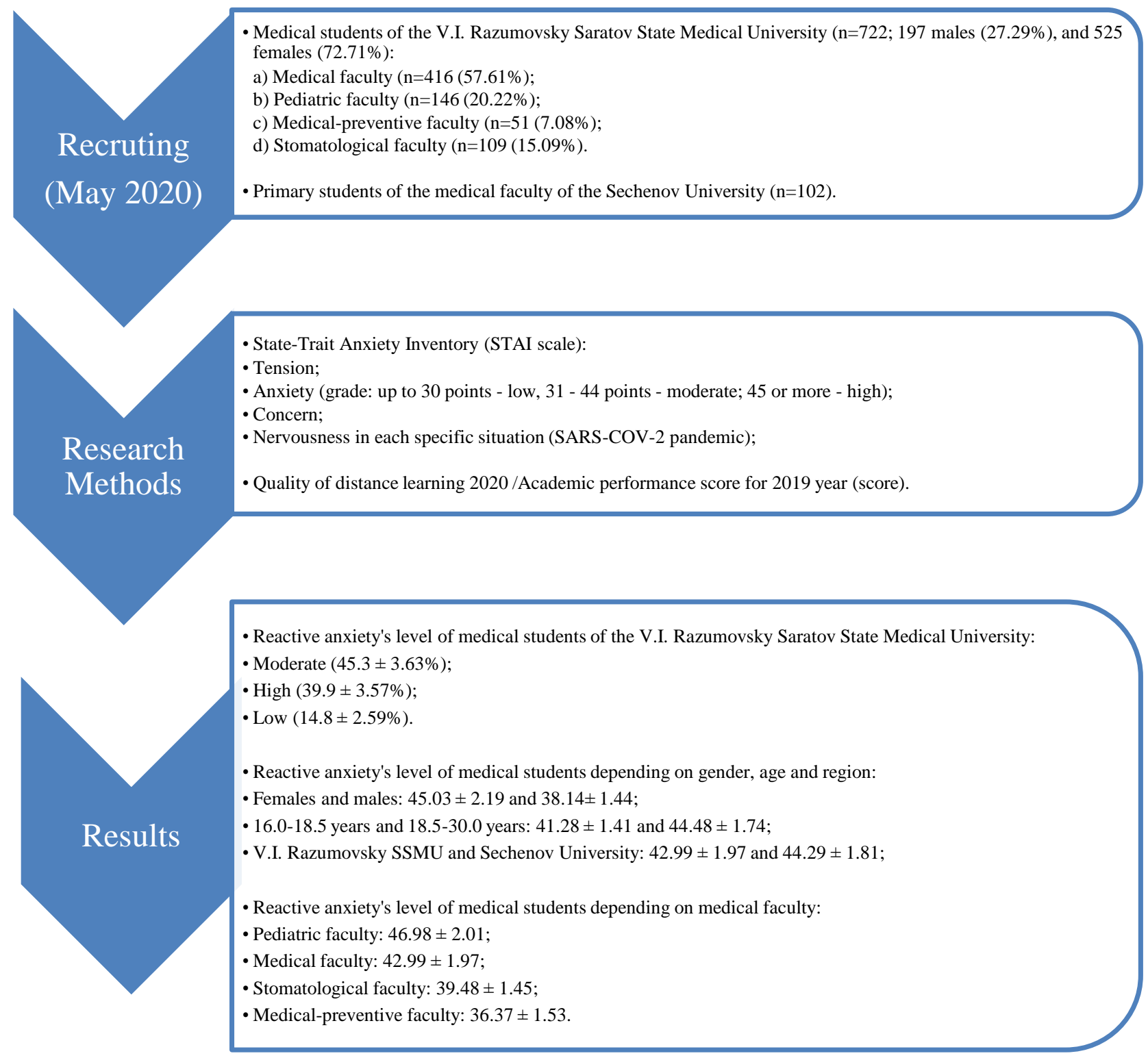

Figure 5. Flowchart of research.

\section{5- Conclusion}

Distance learning helps to prevent the development of more expressed disorders in students living in regions with a tenser sanitary-epidemiological situation. Timely transition to online classes during pandemics contributes to the preservation of the mental students' well-being of and the quality of their educational process. The results of our study established that duration of distance learning for a practical course should not exceed $25 \%$ of the whole course.

\section{6- Declarations}

\section{6-1-Author Contributions}

Conceptualization, O.V.K., O.Yu.A. and S.S.D.; methodology, O.V.K., O.Yu.A., H.M.D.; data analysis, M.V.S. Yu.L.V., A.V.K.; resources O.V.K., O.Yu.A., S.S.D., Yu.L.V, E.D..; writing - original draft preparation, M.V.S., O.V.K., O.Yu.A., E.D.; writing-review and editing, M.V.S., H.M.D., E.D.; project administration S.S.D. All authors have read and agreed to the published version of the manuscript.

\section{6-2-Data Availability Statement}

The data presented in this study are available on request from the corresponding author. The data are not publicly available due to Local Ethical Committee requirements. 


\section{6-3-Funding}

The authors received no financial support for the research, authorship, and/or publication of this article.

\section{6-4-Ethical Approval}

Current research study was approved by the Ethics Committee of First Moscow State Medical University named after I.M.Sechenov (Sechenov University) under protocol №04-19 dated 06.03.2019.

\section{6-5-Conflicts of Interest}

The authors declare that there is no conflict of interests regarding the publication of this manuscript. In addition, the ethical issues, including plagiarism, informed consent, misconduct, data fabrication and/or falsification, double publication and/or submission, and redundancies have been completely observed by the authors.

\section{3- References}

[1] Brooks, Samantha K, Rebecca K Webster, Louise E Smith, Lisa Woodland, Simon Wessely, Neil Greenberg, and Gideon James Rubin. "The Psychological Impact of Quarantine and How to Reduce It: Rapid Review of the Evidence." The Lancet 395, no. 10227 (March 2020): 912-920. doi:10.1016/s0140-6736(20)30460-8.

[2] Serafini, G, B Parmigiani, A. Amerio, A. Aguglia, L Sher, and M Amore. "The Psychological Impact of COVID-19 on the Mental Health in the General Population.” QJM: An International Journal of Medicine 113, no. 8 (June 30, 2020): 531-537. doi:10.1093/qjmed/hcaa201.

[3] Sankova, Maria V., Olesya V. Kytko, Renata D. Meylanova, Yuriy L. Vasil'ev, and Michael V. Nelipa. "Possible Prospects for Using Modern Magnesium Preparations for Increasing Stress Resistance during COVID-19 Pandemic." Research Results in Pharmacology 6, no. 4 (December 29, 2020): 65-76. doi:10.3897/rrpharmacology.6.59407.

[4] Hossain, Md Mahbub, Samia Tasnim, Abida Sultana, Farah Faizah, Hoimonty Mazumder, Liye Zou, E. Lisako J. McKyer, Helal Uddin Ahmed, and Ping Ma. "Epidemiology of Mental Health Problems in COVID-19: a Review." F1000Research 9 (June 23, 2020): 636. doi:10.12688/f1000research.24457.1.

[5] Talevi, Dalila, Valentina Socci, Margherita Carai, Giulia Carnaghi, Serena Faleri, Edoardo Trebbi, Arianna di Bernardo, Francesco Capelli, and Francesca Pacitti. "Mental health outcomes of the CoViD-19 pandemic." Rivista di psichiatria 55, no. 3 (2020): 137-144. doi:10.1708/3382.33569.

[6] Dinakaran, Damodharan, Narayana Manjunatha, Channaveerachari Naveen Kumar, and Bada Math Suresh. "Neuropsychiatric Aspects of COVID-19 Pandemic: A Selective Review." Asian Journal of Psychiatry 53 (October 2020): 102188. doi:10.1016/j.ajp.2020.102188.

[7] Tamm, M.V. "Coronavirus infection in Moscow: forecasts and scenarios." Pharmacoeconomics. Modern pharmacoeconomics and pharmacoepidemiology 13, no. 1 (Jan 2020): 43-51.

[8] Chizhkova, M. B. "Adaptation Dynamics of the First-Year Students to the Educational Environment of the Medical University." Bulletin of Kemerovo State University 21, no. 4 (December 31, 2019): 1039-1049. doi:10.21603/2078-8975-2019-21-4-10391049 .

[9] Romo-Barrientos, Carmen, Juan José Criado-Álvarez, Jaime González-González, Isabel Ubeda-Bañon, Alicia Flores-Cuadrado, Daniel Saiz-Sánchez, Antonio Viñuela, et al. “Anxiety Levels Among Health Sciences Students During Their First Visit to the Dissection Room.” BMC Medical Education 20, no. 1 (April 9, 2020). doi:10.1186/s12909-020-02027-2.

[10] Al-Balas, Mahmoud, Hasan Ibrahim Al-Balas, Hatim M. Jaber, Khaled Obeidat, Hamzeh Al-Balas, Emad A. Aborajooh, Raed Al-Taher, and Bayan Al-Balas. "Distance Learning in Clinical Medical Education amid COVID-19 Pandemic in Jordan: Current Situation, Challenges, and Perspectives." BMC Medical Education 20, no. 1 (October 2020). doi:10.1186/s12909-020-02257-4.

[11] Kötter, Thomas, Josefin Wagner, Linda Brüheim, and Edgar Voltmer. "Perceived Medical School Stress of Undergraduate Medical Students Predicts Academic Performance: An Observational Study.” BMC Medical Education 17, no. 1 (December 2017). doi:10.1186/s12909-017-1091-0.

[12] Zsido, Andras N., Szidalisz A. Teleki, Krisztina Csokasi, Sandor Rozsa, and Szabolcs A. Bandi. "Development of the Short Version of the Spielberger State-trait Anxiety Inventory." Psychiatry Research 291 (September 2020): 113223. doi:10.1016/j.psychres.2020.113223.

[13] Eremina, I. I. "Methodical and technological peculiarities (features) of 1C software products using in the preparation of IT professionals at the university." European Journal of Natural History 4, (April 2016): 64-67.

[14] Racic, Maja, Radica Todorovic, Nedeljka Ivkovic, Srdjan Masic, Bojan Joksimovic, and Milan Kulic. "Self- Perceived Stress in Relation to Anxiety, Depression and Health-Related Quality of Life Among Health Professions Students: A Cross-Sectional Study from Bosnia and Herzegovina." Slovenian Journal of Public Health 56, no. 4 (October 9, 2017): $251-259$. doi:10.1515/sjph-2017-0034. 
[15] McElroy, Eoin, Praveetha Patalay, Bettina Moltrecht, Mark Shevlin, Adrienne Shum, Cathy Creswell, and Polly Waite. "Demographic and Health Factors Associated with Pandemic Anxiety in the Context of COVID-19." British Journal of Health Psychology 25, no. 4 (August 29, 2020): 934-944. doi:10.1111/bjhp.12470.

[16] Wang, Xiaomei, Sudeep Hegde, Changwon Son, Bruce Keller, Alec Smith, and Farzan Sasangohar. "Investigating Mental Health of US College Students during the COVID-19 Pandemic: Cross-Sectional Survey Study.” Journal of Medical Internet Research 22, no. 9 (September 17, 2020): e22817. doi:10.2196/22817.

[17] Chang, Jinghui, Yuxin Yuan, and Dong Wang. "Mental health status and its influencing factors among college students during the epidemic of COVID-19." Nan Fang Yi Ke Da Xue Xue Bao= Journal of Southern Medical University 40, no. 2 (2020): 171 176.

[18] Liu, Cindy H., Emily Zhang, Ga Tin Fifi Wong, Sunah Hyun, and Hyeouk "Chris” Hahm. "Factors Associated with Depression, Anxiety, and PTSD Symptomatology During the COVID-19 Pandemic: Clinical Implications for U.S. Young Adult Mental Health.” Psychiatry Research 290 (August 2020): 113172. doi:10.1016/j.psychres.2020.113172.

[19] Özdin, Selçuk, and Şükriye Bayrak Özdin. "Levels and Predictors of Anxiety, Depression and Health Anxiety during COVID19 Pandemic in Turkish Society: The Importance of Gender.” International Journal of Social Psychiatry 66, no. 5 (May 8, 2020): 504-511. doi:10.1177/0020764020927051.

[20] Gao, Wenjuan, Siqing Ping, and Xinqiao Liu. "Gender Differences in Depression, Anxiety, and Stress among College Students: A Longitudinal Study from China.” Journal of Affective Disorders 263 (February 2020): 292-300. doi:10.1016/j.jad.2019.11.121.

[21] Luibl, Lena, Julia Traversari, Friedrich Paulsen, Michael Scholz, and Pascal Burger. "Resilience and Sense of Coherence in First Year Medical Students - a Cross-Sectional Study." BMC Medical Education 21, no. 1 (March 4, 2021). doi:10.1186/s12909021-02571-5.

[22] Quek, Tam, Tran, Zhang, Zhang, Ho, and Ho. "The Global Prevalence of Anxiety among Medical Students: A Meta-Analysis." International Journal of Environmental Research and Public Health 16, no. 15 (July 31, 2019): 2735. doi:10.3390/ijerph16152735.

[23] Mao, Ying, Ning Zhang, Jinlin Liu, Bin Zhu, Rongxin He, and Xue Wang. “A Systematic Review of Depression and Anxiety in Medical Students in China.” BMC Medical Education 19, no. 1 (September 2, 2019). doi:10.1186/s12909-019-1744-2.

[24] Kebede, Mebratu Abraha, Birke Anbessie, and Getinet Ayano. "Prevalence and Predictors of Depression and Anxiety among Medical Students in Addis Ababa, Ethiopia.” International Journal of Mental Health Systems 13, no. 1 (May 6, 2019). doi:10.1186/s13033-019-0287-6.

[25] Szmyd, Bartosz, Adrian Bartoszek, Filip Franciszek Karuga, Katarzyna Staniecka, Maciej Błaszczyk, and Maciej Radek. "Medical Students and SARS-CoV-2 Vaccination: Attitude and Behaviors." Vaccines 9, no. 2 (February 5, 2021 ): 128. doi:10.3390/vaccines 9020128.

[26] Charkhat Gorgich, Enam Alhagh, Maryam Sarbishegi, Sanam Barfroshan, and Ayub Abedi. "Medical Students Knowledge About Clinical Importance and Effective Teaching Methods of Anatomy." Shiraz E-Medical Journal 18, no. 12 (September 17, 2017). doi:10.5812/semj.14316.

[27] Brassett, Cecilia, Thomas Cosker, D. Ceri Davies, Peter Dockery, Thomas H. Gillingwater, T. Clive Lee, Stefan Milz, Simon H. Parson, Fabio Quondamatteo, and Tracey Wilkinson. “COVID-19 and Anatomy: Stimulus and Initial Response.” Journal of Anatomy (July 6, 2020): 393-403. doi:10.1111/joa.13274. 